\title{
Splenic malignant fibrous histiocytoma with concurrent hypertension and epistaxis in an Alaskan malamute dog
}

\author{
Jung-Hyun Kim, Hee-Jin Kim', Sung-Jun Lee ${ }^{2}$ and Hun-Young Yoon ${ }^{2^{*}}$ (D)
}

\begin{abstract}
Background: Malignant fibrous histiocytoma has been uncommonly described in dogs. Several extranasal neoplasias have been reported to result hypertensive epistaxis. There are, however, no published case reports of extranasal malignant fibrous histiocytoma with concurrent hypertension and epistaxis in dogs.

Case presentation: A 10-year-old dog presented with a spontaneous massive epistaxis persisting for 5 days. The dog exhibited unstable hypertension, which was considered as a cause of epistaxis. The complete blood count, prothrombin time, and activated partial thromboplastin time were within the reference limits, and other systemic examination showed no abnormalities except for a splenic mass occupying more than one third of the abdomen. Histologic examination of the resected spleen revealed the characteristic features of a malignant fibrous histiocytoma. One week after splenectomy, the hypertension and epistaxis resolved clinically and did not recur on the 5-month follow-up.

Conclusions: The dog's blood pressure and epistaxis normalized after malignant fibrous histiocytoma resection suggesting that hypertensive epistaxis may be a rare manifestation of canine malignant fibrous histiocytoma.
\end{abstract}

Keywords: Dog, Epistaxis, Hypertension, Malignant fibrous histiocytoma

\section{Background}

Malignant fibrous histiocytoma (MFH) is a soft tissue sarcoma characterized by the presence of variably fibroblastic to less obviously histiocytic cells and variable numbers of associated non-neoplastic inflammatory cells $[1,2]$. MFH most frequently affects the lung, hilar lymph nodes, mesenteric lymph nodes, liver, and spleen [3], and various reported clinical signs of MFH depend on the tumor location. MFH is associated with a rapid clinical progression, grave prognosis, and usually fatal outcome [4]. Although MFH is the most common type soft tissue sarcoma reported in humans, it has been uncommonly described in veterinary medicine [5]. A previous survey of the types of tumors occurring in dogs found that MFH comprised only $0.34 \%$ of all reported tumors [6]. Generally, MFH is reported in older dogs [2], although one report describes a case involving a puppy [7].

\footnotetext{
* Correspondence: yoonh@konkuk.ac.kr

${ }^{2}$ Department of Veterinary Surgery, College of Veterinary Medicine, Konkuk

University, \#120 Neungdong-ro, Gwangjin-gu, Seoul 143-701, Korea

Full list of author information is available at the end of the article
}

Epistaxis is a common and potentially severe or fatal otolaryngologic emergency in dogs that may be caused by either local disease within the nasal cavity or systemic illness $[8,9]$. Canine epistaxis may be caused by various disorders, including hemostatic abnormalities, neoplasia, infection, foreign bodies, nasal parasites, hyperviscosity syndrome, and vasculitis [9]. In veterinary medicine, systemic hypertension has also been considered as a potential cause of epistaxis, although the direct mechanism remains unclear [8]. Notably, several cases of epistaxis resulting from hypertension or bleeding disorder caused by an extranasal neoplasia have been reported in human and veterinary medicine $[8,10,11]$. However, a link between extranasal MFH with concurrent hypertension and epistaxis has not been reported previously in dogs $[3,4]$. In this report, we present the first description of concurrent hypertension and epistaxis in a dog with a splenic MFH, and the subsequent return of blood pressure values to within reference ranges after splenectomy. Therefore, we review the veterinary literature and suggest the possibility regarding hypertension and epistaxis in a dog with splenic MFH. 


\section{Case presentation}

\section{Medical history and clinical sign}

A 10-year-old spayed female Alaskan malamute (body weight $38 \mathrm{~kg}$ ) was admitted to the Konkuk University Veterinary Medical Teaching Hospital with persistent intermittent bilateral epistaxis of 5 days' duration. Per the owner's report, once initiated, the epistaxis did not stop for $2 \mathrm{~h}$ despite nasal plugging. During the initial physical examination, the dog was bright and alert, with no nasal bleeding. No purpuric spots were observed throughout the body, and an oral examination revealed no remarkable findings. Thoracic auscultation revealed no abnormal sounds in the lung and cardiac fields, and an automated oscillometric blood pressure measurement revealed mild hypertension (systolic blood pressure $148 \mathrm{mmHg}$ ). However, abdominal palpation revealed a large, round, firm, painful mass on the upper-middle abdomen.

\section{Hematology and biochemistry}

Complete blood count, serum biochemistry profile, prothrombin time, and activated partial thromboplastin time analyses were performed to rule out coagulapathies, polycythemia, and thrombocytopenia as causes of epistaxis (Table 1). The complete blood count revealed neutrophilic leukocytosis (white blood cells $42.97 \times 10^{9}$ cells/L; reference range $6-17 \times 10^{9}$ cells/L) and anemia (hematocrit 30\%; reference range $37-55 \%$, hemoglobin $8.7 \mathrm{~g} / \mathrm{dL} ;$ RI $12-18 \mathrm{~g} / \mathrm{dL})$. Serum chemistry revealed mildly elevated alkaline phosphatase activity (378 U/L; reference range $15-127 \mathrm{U} / \mathrm{L}$ ) and hypoalbuminemia ( $2.6 \mathrm{~g} / \mathrm{dL}$; reference range $2.9-4.2 \mathrm{~g} / \mathrm{dL})$. The results of coagulation tests were within reference limits (activated partial thromboplastin time $9.6 \mathrm{~s}$; reference range 14$18 \mathrm{~s}$, prothrombin time $8.2 \mathrm{~s}$; reference range 6.2-8.2 s).

\section{Diagnostic imaging}

Thoracic radiography revealed a mild broncho-interstitial pattern in the overall lung field and a normal cardiac size.

Table 1 The results of coagulation tests, complete blood count, and serum biochemistry profile in a dog presenting with epistaxis

\begin{tabular}{lll}
\hline Variable & Result & Reference Interval \\
\hline PT (seconds) & 8.2 & $6.2-8.2$ \\
APTT (seconds) & 9.6 & $14-18$ \\
WBC $\left(\times 10^{9}\right.$ cells/L) & 42.97 & $6-17$ \\
Haematocrit (\%) & 30 & $37-55$ \\
Platelet $\left(\times 10^{9}\right.$ cells/L) & 239 & $200-500$ \\
Alkaline phosphatase $(\mathrm{U} / \mathrm{L})$ & 378 & $15-127$ \\
Total protein $(\mathrm{g} / \mathrm{dL})$ & 6.8 & $5.4-7.4$ \\
\hline
\end{tabular}

APTT activated partial thromboplastin time, PT prothrombin time, WBC white blood cell
An abdominal ultrasound examination revealed a splenic mass with a heterogeneous appearance and irregular but encapsulated borders.

The dog's owner elected to pursue a rhinoscopy and computed tomography (CT) of entire body. Following anesthetization of the dog, the rhinoscopy was performed using flexible endoscopes (Fig. 1a and b). A retroflexed view of the bilateral nasal choana revealed no remarkable findings except an engorged vessel (Fig. 1c and d), and CT images revealed a normal nasal passage and intact cribriform plate. However, an abdominal CT scan detected a massive, continuous splenic mass measuring $13.2 \mathrm{~cm} \times$ $13.5 \mathrm{~cm} \times 8.4 \mathrm{~cm}$ in the mid-abdomen, as well as diffuse contrast-enhancement of the heterogeneous splenic parenchyma and an irregular margin (Fig. 2a). A thoracic CT scan indicated well-circumscribed, contrast-enhanced miliary nodules on the left cranial lung lobe, consistent with lung metastasis (Fig. 2b). The patient was hospitalized, during which time an episode of intractable and pulsatile epistaxis occurred without cessation for more than $1 \mathrm{~h}$, despite nasal plugging. This episode caused the dog to become slightly agitated, with a temporary severe increase in blood pressure (systolic blood pressure 180-250 mmHg).

\section{Surgery and histopathology}

The owner consented to a surgical excision of the splenic tumor, and the dog underwent a surgical exploration of the abdominal cavity while in the dorsal recumbent position. A large $(16 \mathrm{~cm} \times 14 \mathrm{~cm} \times 10 \mathrm{~cm})$ mass at the tail of the spleen was found to attach to the greater omentum. The involved section of the greater omentum was resected, and a total splenectomy was performed. The abdomen was lavaged with warmed sterile saline and closed routinely. The dog recovered uneventfully with routine postoperative antibiotics. Histopathologically, the resected spleen comprised pleomorphic neoplastic cells; these included both round histiocyte-like cells and spindle cells with occasional multinucleate cells and mitotic activities ranging from one to four mitoses per high-power field (Fig. 3a). An immunohistochemistry stain for vimentin yielded a positive result (Fig. 3b), consistent with the mesenchymal origin, and the main differential diagnosis of spindle cell squamous carcinoma was excluded. A diagnosis of MFH was made based on the histologic and immunohistochemical findings.

\section{Treatment and outcome}

Butorphanol $^{1}(0.1 \mathrm{mg} / \mathrm{kg}$ intravenously every $8 \mathrm{~h})$ was provided as postoperative analgesia for the first $24 \mathrm{~h}$. Although intermittent minor episodes of epistaxis and transient hypertension occurred during the 7 days after splenectomy, the significant epistaxis had disappeared by the 5-month follow-up. Based on the histopathological findings, we recommended that the dog undergo adjuvant 


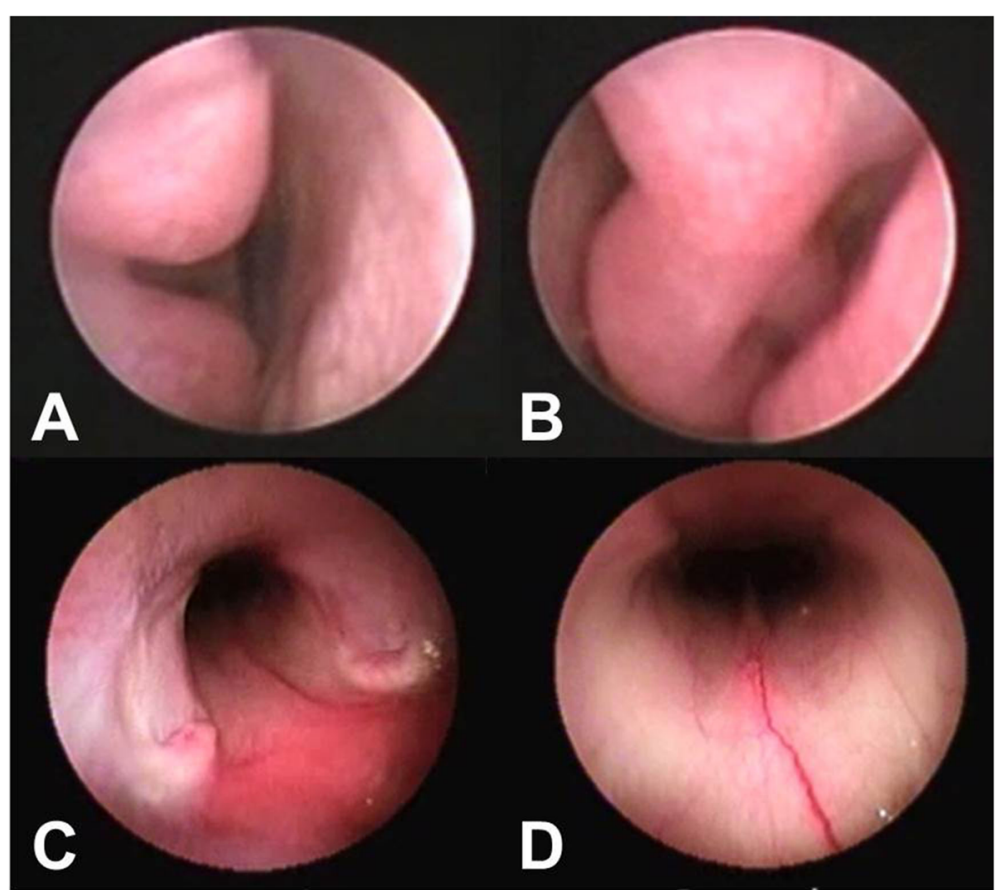

Fig. 1 Rhinoscopy and nasopharyngoscopy did not reveal a mass occupying the nasal and nasopharyngeal regions. Mild congestion was observed in the left (a) and right (b) nasal cavities. Nasopharyngoscopy revealed congestion in the nasopharyngeal region (c) and engorged vessels in the nasal cavity (d)

chemotherapy, but the owners refused. Five months after the first visit, however, the patient presented with acute anorexia and abdominal pain. Although her blood pressure was within normal limits (systolic blood pressure $125 \mathrm{mmHg}$ ), a complete blood count revealed neutrophilic leukocytosis $\left(66.7 \times 10^{9}\right.$ cells/L), anemia (hematocrit $26 \%$, hemoglobin $9.5 \mathrm{~g} / \mathrm{dL}$ ), and thrombocytopenia (platelets $136 \times 10^{9}$ cells $/ \mathrm{L}$; reference range $200-500 \times 10^{9}$ cells/ L). A serum chemistry analysis detected elevated hepatic enzyme levels (aspartate aminotransferase 84 U/L, RI 0$50 \mathrm{U} / \mathrm{L}$, alkaline phosphatase activity $1260 \mathrm{U} / \mathrm{L}$, gamma glutamyl transferase $14 \mathrm{U} / \mathrm{L}$; reference range $0-7 \mathrm{U} / \mathrm{L}$ ) and mild hypertriglyceridemia $(173 \mathrm{mg} / \mathrm{dL}$; reference range $10-100 \mathrm{mg} / \mathrm{dL}$ ). An abdominal ultrasound revealed multiple nodules and masses of various sizes, shapes, and echogenecities that were spread diffusely throughout all liver lobes, leading to the diagnosis of metastatic liver masses and nodules. However, the owner declined further examinations and therapy because of the poor prognosis, and the patient was discharged at the owner's request. The dog died 3 days later at home; however, the owner unfortunately refused a necropsy.

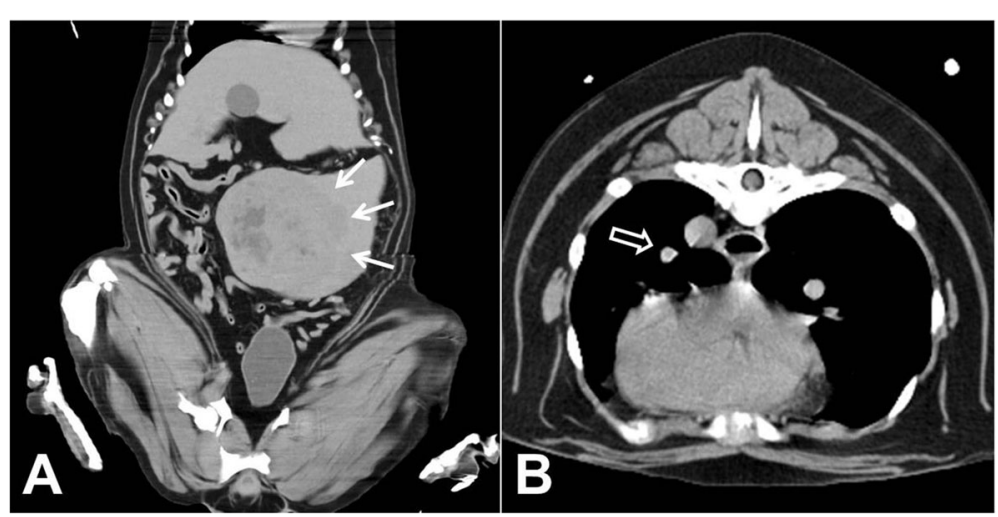

Fig. 2 Computed tomography of the (a) abdomen and (b) thorax. a A mass continuous with the splenic parenchyma was detected in the mid-abdomen. Note the diffuse heterogeneous contrast enhancement of the splenic parenchyma and irregular margin (mass size: $13.2 \mathrm{~cm} \times 13.5 \mathrm{~cm} \times 8.4 \mathrm{~cm})($ arrows). b Imaging of the thorax revealed a well-circumscribed, contrast-enhanced miliary nodule on the left cranial lung lobe (open arrow) 


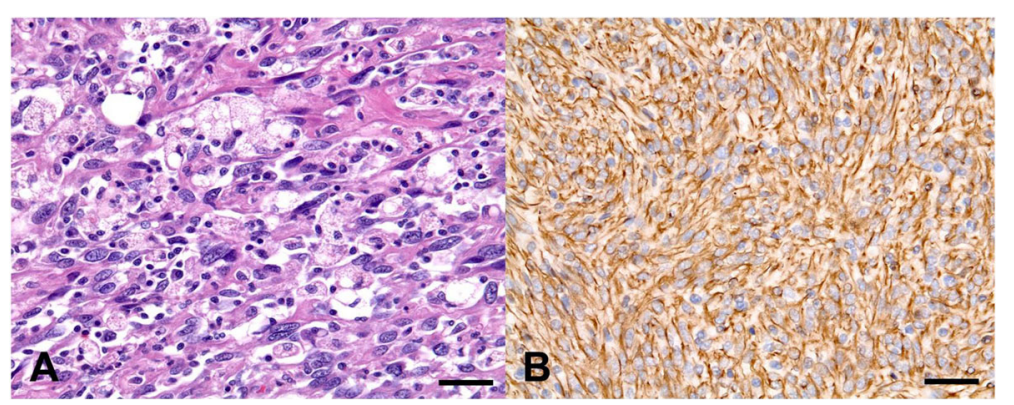

Fig. 3 Histopathology of a malignant fibrous histiocytoma resected from the spleen. a Note the plump, spindle-shaped fibroblasts and histiocytelike cells and the storiform pattern. Oval or polygonal malignant spindle cells with anisokaryosis and coarse nuclei, as well as scattered inflammatory cells, are shown (hematoxylin and eosin, magnification $\times 400$, scale bar $=35 \mu \mathrm{m}$ ). b Immunohistochemically, the tumor cells were strongly positive for vimentin (magnification $\times 400$, scale bar $=35 \mu \mathrm{m}$ )

\section{Discussion}

To the authors' knowledge, no previous report has described concurrent hypertension and epistaxis in the dog with MFH. In the present case, the hypertension and epistaxis resolved after the surgical resection of MFH. Accordingly, this the first report of concurrent systemic hypertension and epistaxis attributable to MFH in a dog, with resolution after splenectomy. The lack of clinical reports describing these concurrent diseases processes might be attributable either to the low prevalence of splenic MFH in dogs or the fact that blood pressure evaluations are not routinely performed when abdominal masses are detected.

Epistaxis may be caused by local disease within the nasal cavity or by systemic diseases that result in hemostatic disorders [9]. In a retrospective study of 176 dogs with epistaxis, the condition was predominantly attributed to local causes ( $83 \%$ vs. $17 \%$ systemic) [8]. In the present case, we did not detect any mass, inflammation, infection, or foreign body in the nasal cavity and nasopharynx of the dog. However, the present dog's indirect systolic blood pressure was above the reference range, and therefore epistaxis might be attributable to hypertension. In an earlier veterinary medicine case, excessive and tortuous vessels were observed in the caudal rhinoscopy of a hypertensive cat with epistaxis [12]. In the present case, a nasopharyngoscopic examination revealed marked vascular engorgement in the nasal mucosa. Accordingly, the resection of the splenic MFH appeared sufficient to normalize the blood pressure and resolve epistaxis in the present canine patient.

In dogs, hypertension generally develops at an older age and more commonly affects males than females [13]. The most common diseases associated with canine hypertension are renal disease, cardiac left ventricular hypertrophy, hyperadrenocorticism, pheochromocytoma, and diabetes mellitus, whereas less commonly associated diseases include primary hyperaldosteronism, hyperthyroidism, obesity, and idiopathic hypertension [14]. In the present case, unfortunately, we were unable to perform evaluations of cardiac or hormonal factors (e.g., cortisol, dopamine, aldosterone, thyroxine); however, the hypertension resolved after splenectomy. Common clinical signs of hypertension in dogs include blindness or visual disturbances, although seizures and epistaxis may also present [14]. In hypertensive veterinary patients, risk of ocular injury increases when the systolic BP exceeds $180 \mathrm{mmHg}[14,15]$. In the present case, no ocular lesions (e.g., retinal detachment, retinal hemorrhage, retinal perivascular edema, papilledema, vitreal hemorrhage, hyphema, secondary glaucoma, retinal degeneration) were observed, possibly because the episodes of hypertension exceeding $180 \mathrm{mmHg}$ were transient and returned to normal values within a week.

The surgical resection of a MFH to control concurrent systemic hypertension in a dog has not previously been reported. In the present case, the hypertension was suspected to be caused by the MFH; therefore, its removal would theoretically reduce the blood pressure to within reference limits. Indeed, after splenectomy, the systolic blood pressure in the dog returned to normal and the epistaxis subsequently disappeared. The significance of the relationship between MFH and hypertensive epistaxis in the present case is unclear because epistaxis occurs even in healthy dogs. However, given the effectiveness of MFH resection in this dog, further investigations are needed to clarify the relationship between MFH and hypertensive epistaxis.

In older dogs, splenic masses are commonly occurred and may be malignant, benign, or non-neoplastic [16]. Several studies have reported that about $2 / 3$ of canine splenic masses are malignant, and the most prevalent malignant splenic tumor is hemangiosarcoma [16, 17]. Additionally, various sarcomas, lymphoma, and MFH have been reported as malignant splenic masses $[18,19]$. A diagnosis of MFH based on histological morphology is almost insufficient [20]. Therefore, for more accurate diagnosis, additional diagnostic methods are needed, 
including immunology and molecular approaches. The present study report diagnosis of MFH uses not only histological morphology, but also immunohistochemistry to investigate the origin of the tumor. In both humans and dogs, vimentin expression has been widely used to confirm the mesenchymal origins of tumors [21]. In this case, hematoxylin and eosin staining and immunoreactivity for vimentin led us to conclude that the tumor was a sarcoma and to make a final diagnosis of MFH. Furthermore, three types of MFH have been reported in dogs: giant cell, inflammatory, and storiform-pleomorphic [21]. Special staining techniques assisted classification of MFH, and several studies reported both histochemical staining and immunostaining including anti-actin, anti-desmin, anti-momonocytes/macrophages antibody were able to help in the classification of MFH into the three different subgroups in dogs [21, 22]. Additional diagnostic marker such as anti-S100 has been also reported to differentiate MFH from other malignant sarcoma [23]. However, definitive immunohistochemical staining patterns have not been clearly identified for MFH in veterinary medicine [21]. As multiple morphologic types may be detected in a single tumor, MFHs are usually classified by their predominant features. Accordingly, the tumor in the dog described here is most consistent with storiform-pleomorphic type MFH based on the histopathologic examination results. In human medicine, the variants of MFH have different clinical significances, and a MFH with marked inflammation is associated with a better prognosis, compared with the storiform-pleomorphic variant [24]. By contrast, the relationship between the histopathological variant and prognosis has not been reported in the context of veterinary medicine. Generally, veterinary cases of MFH have been reported as single and often locally invasive tumors, whereas metastasis is rare $[1,6]$. In the present case, evidence of metastasis to the lung was evident from a CT examination at the time of the initial diagnosis. Additionally, the dog's condition began to deteriorate at 5 months after the initial presentation, at which time new, variously sized nodules were detected during an ultrasonographic examination of the liver.

In the present study, the nasal examinations which included CT and rhinoscopy, yielded no remarkable findings, and the cause of epistaxis remains unknown. We suggest two possibilities regarding hypertension and epistaxis in this dog with MFH. First, the dog might have previously exhibited hypertension and subsequent vascular abnormalities which is commonly referred to as a target-organ damage in the veterinary medicine [14], and would therefore have been prone to epistaxis, particularly in response to pain-induced abnormal blood pressure elevations caused by the massive splenic MFH. Second, idiopathic epistaxis might cause an arousal reaction because the nasal cavity is a region of rich autonomous innervation [25], and this anxiety might manifest as transient hypertension. Accordingly epistaxis may have also been a potent trigger for hyperresponsiveness (e.g., hypertension) in the present canine case.

\section{Conclusions}

We report herein the clinical course of hypertensive epistaxis with the putative complication of splenic MFH in a dog. This is the first report of such a case in the literature. Although MFH is an extremely rare cause of the clinical signs observed in this dog, it should be considered in the differential diagnosis for uncontrolled epistaxis without clotting profile abnormalities. Furthermore, our findings warrant an investigation of biological behaviors in a larger number of cases and follow-up blood pressure evaluations in dogs with malignant tumors.

\section{Endnotes \\ ${ }^{1}$ Butophan Inj, Myungmoon Pharm, Seoul, Korea.}

\section{Abbreviations \\ CT: Computed tomography; MFH: Malignant fibrous histiocytoma}

\section{Authors' contributions \\ JHK: This author wrote the article and contributed to the clinical assessment, diagnosis, treatment and follow-up of the case. HJK: This author contributed to the initial clinical assessment and diagnostic work-up of the case, pro- vided images, and helped to write the manuscript. SJL: This author contrib- uted to the surgery and post-operative management of the case, and helped to write the manuscript. HYY: This author supervised the clinical as- sessment, diagnosis, and treatment of the case and helped to write the manuscript. All authors read and approved the final manuscript.}

\section{Authors' information}

$J H K$ is a clinical professor in veterinary internal medicine at Konkuk University Veterinary Teaching Hospital (KU-VTH). HJK is a DVM working in clinical veterinary internal medicine at KU-VHT under the supervision of JHK. SJL is a DVM working in clinical veterinary surgery at KU-VHT. HYY is an associated professor in veterinary surgery at Konkuk University.

\section{Ethics approval}

The patient's owner provided written, informed consent for the clinical assessment, diagnostic work-up, treatment and follow-up of their pet.

\section{Consent for publication}

Not applicable.

\section{Competing interests}

The authors declare that they have no competing interests.

\section{Publisher's Note}

Springer Nature remains neutral with regard to jurisdictional claims in published maps and institutional affiliations.

\section{Author details}

'Department of Veterinary Internal Medicine, Konkuk University Veterinary Medical Teaching Hospital, \#120 Neungdong-ro, Gwangjin-gu, Seoul 143-701, Korea. ${ }^{2}$ Department of Veterinary Surgery, College of Veterinary Medicine, Konkuk University, \#120 Neungdong-ro, Gwangjin-gu, Seoul 143-701, Korea. 
Received: 8 January 2018 Accepted: 7 August 2018

Published online: 13 August 2018

\section{References}

1. Gleiser CA, Raulston GL, Jardine JH, Gray KN. Malignant fibrous histiocytoma in dogs and cats. Vet Pathol. 1979;16:199-208.

2. Kerlin R, Hendrick M. Malignant fibrous histiocytoma and malignant histiocytosis in the dog — convergent or divergent phenotypic differentiation? Vet Pathol. 1996:33:713-6.

3. Schmidt ML, Rutteman GR, van Niel MH, Wolvekamp PT. Clinical and radiographic manifestations of canine malignant histiocytosis. Vet Q. 1993;15:117-20.

4. Liptak JM, Forrest LJ. Soft tissue sarcomas. In: Withrow SJ, Vail DM, Page RL, editors. Small animal clinical oncology. 5th ed. Philadelphia: WB Saunders; 2013. p. 356-80.

5. Kiran MM, Karaman M, Hatipoglu F, Koc Y. Malignant fibrous histiocytoma in a dog: a case report. Vet Med Czech. 2005;50:553-7.

6. Waters CB, Morrison WB, DeNicola DB, Widmer WR, White MR. Giant cell variant of malignant fibrous histiocytoma in dogs: 10 cases (1986-1993). J Am Vet Med Assoc. 1994;205:1420-4.

7. Pires M. Malignant fibrous histiocytoma in a puppy. Vet Rec. 1997;140:234-5.

8. Bissett SA, Drobatz KJ, McKnight A, Degernes LA. Prevalence, clinical features, and causes of epistaxis in dogs: 176 cases (1996-2001). J Am Vet Med Assoc. 2007;231:1843-50.

9. Strasser $J L$, Hawkins EC. Clinical features of epistaxis in dogs: a retrospective study of 35 cases (1999-2002). J Am Anim Hosp Assoc. 2005;41:179-84.

10. Schloendorff G. Severe arterial epistaxis in pheochromocytoma. Z Laryngol Rhinol Otol. 1962;41:700-3.

11. Talei A. Splenic hamartoma: a case report. Med J Islam Repub Iran. 1997;11:57-9.

12. Aoki T, Madarame H, Sugimoto K, Sunahara H, Fujii Y, Kanai E, Ito T. Diode laser coagulation for the treatment of epistaxis in a Scottish fold cat. Can Vet J. 2015;56:745-8.

13. Henik RA. Systemic hypertension and its management. Vet Clin North Am Small Anim Pract. 1997:27:1355-72.

14. Brown S, Atkins C, Bagley R, Carr A, Cowgill L, Davidson M, Egner B, Elliott J, Henik R, Labato M, Littman M, Polzin D, Ross L, Snyder P, Stepien R. Guidelines for the identification, evaluation, and management of systemic hypertension in dogs and cats. J Vet Intern Med. 2007:21:542-58.

15. Sansom J, Barnett KC, Dunn KA, Smith KC, Dennis R. Ocular disease associated with hypertension in 16 cats. J Small Anim Pract. 1994;35:604-11.

16. Grimes JA, Prasad N, Levy S, Cattley R, Lindley S, Boothe HW, Henderson RA, Smith BF. A comparison of microRNA expression profiles from splenic hemangiosarcoma, splenic nodular hyperplasia, and normal spleens of dogs. BMC Vet Res. 2016;12:272.

17. Spangler WL, Culbertson MR. Prevalence, type, and importance of splenic diseases in dogs: 1,480 cases (1985-1989). J Am Vet Med Assoc. 1992;200:829-34.

18. Hammond TN, Pesillo-Crosby SA. Prevalence of hemangiosarcoma in anemic dogs with a splenic mass and hemoperitoneum requiring a transfusion: 71 cases (2003-2005). J Am Vet Med Assoc. 2008:232:553-8.

19. Eberle N, von Babo V, Nolte I, Baumgartner W, Betz D. Splenic masses in dogs. Part 1: Epidemiologic, clinical characteristics as well as histopathologic diagnosis in 249 cases (2000-2011). Tierarztl Prax Ausg K Kleintiere Heimtiere. 2012;40:250-60.

20. Ko JS, Kim HJ, Choi YM, Kim JW, Park C, Do SH. Diagnostic approach to malignant fibrous histiocytomas of soft tissue in dogs: a case report. Vet Med Czech. 2013:58:621-7.

21. Morris JS, McInnes EF, Bostock DE, Hoather TM, Dobson JM Immunohistochemical and histopathologic features of 14 malignant fibrous histiocytomas from flat-coated retrievers. Vet Pathol Online. 2002;39:473-9.

22. Do SH, Hong IH, Park JK, Ji AR, Kim TH, Kwak DM, Jeong KS. Two different types of malignant fibrous histiocytomas from pet dogs. J Vet Sci. 2009:10:169-71.

23. Makovicky P, Makovicky P, Nagy M, Nemeth P, Rajmon R. Differentiation of malignant fibrous histiocytoma and pleomorphic liposarcoma in dogs, using anti-S-100 protein antibody Immunohistochemical case report. Magyar Allatorvosok Lapja. 2012;134:101-5.

24. Enzinger FM, Weiss SW. Malignant tumors of uncertain histogenesis. In: Enzinger FM, Weiss SW, editors. Soft tissue tumors. 2nd ed. St. Louis: Mosby; 1988. p. 929-65.

25. Schmiedt CW, Creevy KE. Nasal planum, nasal caivity, and sinuses. In: Tobias KM, Johnston SA, editors. Veterinary surgery: small animal. 1st ed. St. Louis: Saunders; 2012. p. 1691-706.

Ready to submit your research? Choose BMC and benefit from:

- fast, convenient online submission

- thorough peer review by experienced researchers in your field

- rapid publication on acceptance

- support for research data, including large and complex data types

- gold Open Access which fosters wider collaboration and increased citations

- maximum visibility for your research: over $100 \mathrm{M}$ website views per year

At BMC, research is always in progress.

Learn more biomedcentral.com/submissions 